Applied Chemistry for Engineers

By Dr. Eric S. Gyngell. Pp. viii+328. (London : Edward Arnold and Co., 1940.) 15s. net.

7 HIS small volume presents in a particularly happy manner an account of many materials used by the engineer and the processes by which they are made, or in which they are used. There are no lengthy tables of analyses or detailed accounts of laboratory methods, but, instead, general descriptions and careful explanations of many terms, such as, for example, 'gas coal', 'cetane number', 'differential aeration' and 'continuous blowdown', with which the engineer is probably familiar, but might have difficulty in defining.

More than half the book is devoted to fuels and combustion, but in view of the fact that the subjects dealt with are, among others, the nature of fuels, gases and their manufacture, the distillation and synthesis of liquid fuels, methods of combustion and thermal calculations, this cannot be considered excessive.

Forty-nine pages suffice for a comprehensive account of the principles underlying corrosion and its prevention, while the remaining chapters deal briefly with paints, water treatment, cements and lubrication. So brief are these that at first sight they would appear scarcely worth inclusion, but careful scrutiny reveals the fact that the author's gift of condensation is such that very few salient points have escaped notice. A little more information about modern paints would be valuable, and perhaps a future edition will contain a chapter on plastics.

This notice would not be complete without reference to the 135 diagrams, which combine small size with remarkable clarity. Finally, although the book is written for engineers, it should be read by every student of chemistry who wishes to acquire an insight into something more than the purely theoretical side of his science.

H. E. W.

\section{A Textbook of Dietetics}

By Dr. L. S. P. Davidson and Ian A. Anderson; with Diet Sheets constructed by Miss Mary E. Thomson. Pp. xviii+324. (London: Hamish Hamilton Medical Books, 1940.) 10s. 6d. net.

$\mathrm{T}$ HE unprejudiced reader will cordially endorse the appreciation of Sir John Orr, the director of the Rowett Institute for Research in Animal Nutrition, Aberdeen, when he says in the foreword of this book that the practitioner will find in it not only precise and detailed guidance for dietetic treatment, but also a scientific and lucid account of the recently acquired knowledge on nutrition on which suck treatment is based. The book, which is based or, courses of lectures on the physiology of nutrition and the practice of dietetics given for several years to students in the University of Aberdeen, is divided into five parts. The first consists of a general survey of the nation's diet, past and present, with special reference to the diet at various levels of income, and the experimental, clinical and sociological data on the relation of diet to health and fitness. The second part contains a clinically complete account of the physiology of nutrition. Much of the material in this section (particularly on the vitamins) is based on very recent experimental and clinical studies. The third part is devoted to diet in health, including problems of diet in childhood, pregnancy, lactation, training and war-time. In the fourth part the dietetic treatment of established diseases is discussed. The fifth part consists of tables, recipes and diet sheets, the last of which have been constructed by Miss Mary E. Thomson, sister-dietitian to the Royal Infirmary, Aberdeen.

A bibliography of recent and almost exclusively British and American literature is appended.

The eminently practical and up-to-date character of the work renders it a most desirable addition to the library of a medical man.

\section{Diseases of Poultry}

Their Aetiology, Diagnosis, Treatment and Control ; with a Section on the Normal Anatomy and Physiology of the Fowl. By Ernest Gray. (Lockwood's Agricultural and Horticultural Handbooks.) Pp. $\mathrm{x}+198+16$ plates. (London: Crosby Lockwood and Son, Ltd., 1940.) 9s. 6d. net.

VERY few veterinary surgeons have thought fit to write a book on diseases of poultry. Mr. Ernest Gray has done justice to the subject and is to be congratulated on his effort. A book of this size, written by one with specialized knowledge, will add to the value of any library or private bookshelf.

Naturally a good deal of the reading matter is dry and somewhat unappetizing, but this is unavoidable in a book of this character. The section dealing with specific poultry diseases is more readable than the chapters on anatomy, physiology, pathology and feeding. The book is exceedingly well illustrated and the illustrations should prove of great value to the novice when desirous of getting to the 'root of the evil'. The author makes frequent references to writings by American workers, and also refers to some recent work by British specialists.

The book would appear to fill a place between the cheap British publications on this subject and the expensive but comprehensive works recently published in the United States.

H. Howes.

\section{Garden Science}

By Dr. John Grainger. Cheaper edition. Pp. 265. (London : University of London Press, Ltd., 1940.) $2 s$. $6 d$. net.

7 HE re-issue of this work at such an astonishingly low price will be welcomed by all those who are familiar with the earlier edition. It is designed to meet the needs of amateur gardeners, horticultural and agricultural students, as well as pupils of matriculation standard. Characteristics of seed and vegetative propagation, plant growth and its control by the gardener, problems of plant sterility and of pest and disease control are discussed, while considerable prominence is given to descriptions of methods used for raising improved varieties of plants, the planning of experiments and of educationa] gardens. 